\title{
Multi-agent Model for Urban Goods Distribution
}

\author{
Martín Darío Arango Serna ${ }^{1}$, Cristian Giovanny Gómez Marín ${ }^{1}$, \\ Conrado Augusto Serna Urán ${ }^{2}$, Julián Andrés Zapata Córtes ${ }^{3}$ \\ ${ }^{1}$ Universidad Nacional de Colombia, Sede Medellín, Medellín, \\ Colombia \\ ${ }^{2}$ Universidad de San Buenaventura, Seccional Medellín, Medellín, \\ Colombia \\ ${ }^{3}$ Institución Universitaria CEIPA, Sabaneta, Antioquia, \\ Colombia \\ mdarango@unal.edu.co
}

\begin{abstract}
This paper proposes a multi-agent model to evaluate the last mile distribution process in urban areas, in a network that includes a single depot, multiple customers and multiple homogeneous and capacitated vehicles. The model is based on the behaviors of the different stakeholders and their interactions, including coordination and collaboration of agents in the allocations and routing processes. The performance of the Solomon Algorithm is the starting point of the proposed model and the comparison of both results shows the advantage of using multi-agent modelling to reduce distances and number of vehicles needed for urban freight transportation.
\end{abstract}

Keywords: multi-agent model, memetic algorithm, urban freight transport, collaboration.

\section{Introduction}

City logistics refers to the optimization of all the logistics and transport activities in urban areas, considering the environment, traffic, security impacts and energy savings [1-3]. It implies a complex system that involves transport processes, urban dynamics, and infrastructure planning and logistics strategies for all stakeholders that should work with an integrated and coordinated methodology to achieve better results [4]. According to Wolpert and Reuter [5], the main stakeholders in Urban Goods Distribution (UGD) are: carriers, public authorities, receivers, residents and shippers, each one with different behaviors and objectives. Other stakeholders that can be included are the urban consolidation centers and road operators. As all stakeholders have very different objectives, they should work coordinated with the aim to improve the urban freight transport performance.

Multi-Agent System (MAS) Modeling is an approach used in UGD that considers different stakeholders and their behaviors and interactions in several scenarios and 
policies changes as a support system for strategic, tactic and operative decisions. MAS can represent the reality of the UDG, the relationships between stakeholders and their behaviors as autonomous agents with the ability to collaborate [6]. MAS can represent city logistics systems in a flexible and natural way with the aim of understand and forecast policy measures and help to increase the efficiency and reduce the externalities of city logistics [7].

In this paper, a multi-agent model that considers the stakeholders involved in a single depot network with $n$ customers and $k$ homogeneous unlimited and capacitated vehicles is used to evaluate the last mile distribution process in urban areas. The model includes logistics behaviors, interactions and uses a heuristic algorithm to improve the performance of UGD system.

An initial allocation and routing to last mile distribution is obtained by the Solomon heuristic that is a benchmark solution to the capacitated vehicle routing problem with time windows. These initial routes are analyzed and compared with those generated by the proposed MAS model.

\section{Multi-Agent Systems in Goods Distribution}

There are many strategies used in urban goods distribution [8-10]. These strategies consider different distribution structures that involve the goods flow from origin to destination and the space-temporal patterns in the vehicle routing in distribution systems. MAS modeling is a used as an approach in UGD because of its ability to consider different stakeholders, their behaviors and interactions in several scenarios and policies changes and how these changes affect the decision making process. Other important MAS characteristic is that it can handle complex systems with large numbers of heterogeneous and autonomous agents which can interact and collaborate between them $[7,12]$.

According to Wooldridge [13] Agents are computer systems with two important capabilities: First, they have the capacity to carry out autonomous actions; second, they can interact with other agents, not only through data interchange, but also real social relationships such as coordination, cooperation and negotiation, among others. An agent can have a collection of several actions that can be performed in the interaction with its environment, which may also include other agents. The issue to the agent is deciding what actions to take to meet their internal goals [14].

A MAS organizes agents according to their characteristics and abilities to access jointly, but also in a decentralized manner to the environment in which exist and solve common and individual objectives. For this, a series of communication, coordination and negotiation protocols is established among the agents. In this case, collaboration between the system components facilitates problems solving and reaching out the defined objectives [11-15].

The application of MAS in transport system has been used in several research studies for transportation problems, but in logistics and urban freight transport there is too much work to do [16]. Some researches that use MAS for transport are [17-21] and for Urban Goods Distribution are [14, 22, 23-27]. 


\section{$3 \quad$ Methodology}

\subsection{Urban Distribution Problem}

The UGD could be performed with different strategies that implies specific structures and typologies [9]. The focus of this paper is the last mile distribution and operative decisions, where a single product is delivered to a set of customers from a unique depot or satellite. The depot has no limitation for the number of homogenous capacitated vehicles. This problem can be described as a capacitated vehicle routing problem with time windows (CVRPTW) and the objective is the minimization of total delivery cost. The mathematical model for the CVRPTW expressed by Zulvia et al. [28] is:

$$
\sum_{k=1}^{h} \sum_{i=0}^{n} \sum_{j=0}^{n} c_{i j x_{i j}^{k}}
$$

where $c_{i j}$ is the travel cost from customer $i$ to $j$, the depot is the customer 0 , and $x_{i j}^{k}$ represent decision variable defined in (2):

$$
x_{i j}^{k}=\left\{\begin{array}{c}
1 \text { if the vehicle } k \text { travel from customer i to } j, \\
0 \text { otherwise }
\end{array}\right.
$$

constrained to:

$$
\begin{gathered}
\sum_{i=0}^{n} x_{i 0}^{k}-\sum_{j=0}^{n} x_{0 j}^{k}=0, \quad \forall k=1, \ldots, h, \\
\sum_{i=0}^{n} \sum_{k=1}^{h} x_{i j}^{k}=1, \quad \forall j=1,2, \ldots, n, \\
\sum_{j=0}^{n} \sum_{k=1}^{h} x_{i j}^{k}=1, \quad \forall i=1,2, \ldots, n, \\
\sum_{j=0}^{n} x_{0 j}^{k}=1, \quad \forall k=1,2, \ldots h, \\
\sum_{i=0}^{n} x_{i 0}^{k}=1, \quad \forall k=1,2, \ldots, h, \\
\sum_{j=1}^{n} \sum_{i=0}^{n} q_{i} x_{i j}^{k} \leq C, \quad \forall k=1,2, \ldots, h, \\
q_{i} \leq r_{i}^{k} \leq C, \forall i=1,2, \ldots, n ; k=1,2, \ldots, h,
\end{gathered}
$$




$$
\begin{gathered}
\sum_{i=0}^{n} x_{i j}^{k}-\sum_{i=0}^{n} x_{j i}^{k}=1, \forall j=1,2, \ldots, n ; k=1, \ldots, h, \\
r_{i}^{k}+q_{j}-r_{j}^{k} \leq C\left(1-x_{i j}^{k}\right), \forall i=0,1, \ldots n ; j=1,2, \ldots, h, \\
s_{j}^{k}=\max \left\{e_{j}, s_{i}^{k}+u_{i}^{k}+t_{i j}\right\}, \quad \text { if } x_{i j}^{k}=1, \\
s_{j}^{k}+u_{j}^{k} \leq 1 . \\
\text { Agent Control } \\
\text { Agent terminal } \\
\begin{array}{l}
\text { Assesses capacities and vehicles } \\
\text { resources to fulfill the } \\
\text { customer's orders }
\end{array} \\
\begin{array}{l}
\text { Designs the routes and assigns } \\
\text { vehicles }
\end{array} \\
\begin{array}{l}
\text { Performs an evolutionary process } \\
\text { of collaboration and coordination } \\
\text { between vehicles }
\end{array}
\end{gathered}
$$
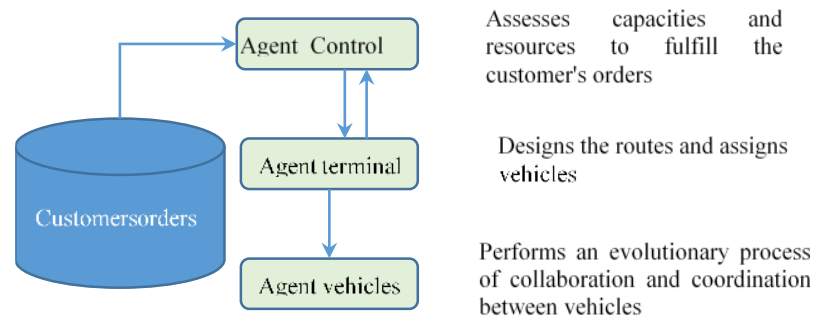

Performs an evolutionary process

Fig. 1. Multi-agent framework to UGD.

Equation 3 is a constraint that ensures that every vehicle starts and finishes at the depot. Constraints 4 and 5 ensure that each customer is visited just once and constraints 6 and 7 ensure that each vehicle is used once. The capacity constraints are expressed in equations 8 and 9 , where the demand of the customer $i$ is denoted by $q_{i}$, the load of each vehicle after visiting each customer must be greater than zero $r_{i}^{k}>0$.

Equation 10 and 11 ensure connectivity between the created subtours. Equation 12 and 13 express the time window constraints, where $e_{j}$ is the earliest time to deliver at customer $j, l_{j}$ is the latest time to deliver at customer $j$, the beginning of the service time of the vehicle $\mathrm{k}$ for the customer $j$ is $s_{j}^{k}$ and $u_{i}^{k}$ and $t_{i j}$ are the time required to serve the customer $i$ and the travel time from customer $i$ to $j$, respectively.

The most common heuristic used to solve this type of problem is the Solomon insertion heuristic [29] that will be used as a benchmark to compare the proposed model solution. Although this heuristic is recognized as a good solution method, we propose a multi-agent model to improve the solutions generated by the former heuristic.

\subsection{The Multi-Agent Model}

The proposed framework to solve the problem of a single depot with $n$ customers and $k$ homogenous capacitated vehicles is a Multi-Agent Model with a memetic algorithm. It allows the collaboration and coordination between the vehicles in order to improve the routes in terms of travel distance and number of vehicles. The multi-agent model considers the demands, the time windows constraints of customers and the capacity of the vehicles for the assignment of each customer to a different vehicle. 
It also considers the process of coordination and collaboration between the agents to establish routes that improve deliveries efficiency while fulfilling the customers' requirements, Fig. 1 presents the agents defined in the proposed MAS model.

The proposed MAS model integrates autonomous agents with reactive, proactive and social characteristics, based on the FIPA-ACL language (language of communication among agents) proposed by the Foundation for Intelligent Physical Agents [30] looking for improving the assignment the customers according to the available capacity in the terminal and in the vehicles, as well as design routes that make efficient deliveries in the terms of the established requirements of customers. This process involves many activities of communication and coordination between the different stakeholders of this distribution network.

The control agent has direct contact with the demands of the customer database, reads all the set of client's needs, assesses the capacities and resources of the logistics network, accepts or rejects the customers' orders and activates all the assignment process to the other agents by a Query protocol with the agent terminal. The Query Protocol allows the agent control to ask the agent terminal if it can accept the customer's orders and the agent terminal answers if it agrees with the request or rejects it.

The agent terminal receives the information and designs the initial route by the Solomon heuristic with the number of vehicles needed to perform the routes, the travel distance and the used capacity through a Request Protocol to the vehicles requesting the service of deliveries.

The agent vehicle uses an evolutionary heuristic algorithm that allows solve optimize the problem with global and local search strategies, but with the advantage of autonomy provided by the multi-agent system. Each vehicle is an agent that evolves from the interaction with other vehicles and negotiates the best possible interchange of clients to reduce the cost of the distribution [14]. Each agent has two properties: the set of clients assigned to its route, that defines its phenotype and a gender that will allow interactions with other agents and according to [31] the believes of the agents stablishes the set of genes that can crossover their genes and it's conditioned by the gender of the agents $v$ and the fitness value $(f)$ of their phenotype $l$. The believes of the agents can be denoted as the follow [14]:

$$
B_{i}=\left\{\begin{array}{c}
g_{i} \neq g_{j} \\
\left(\frac{f_{i}-f_{j}}{f_{i}+f_{j}}\right)>\alpha, \quad 0>\alpha \leq 1
\end{array}\right\} i, j \text { are agents } \in\left\{v_{1}, v_{2}, \ldots v_{n}\right\} .
$$

The first part of the equation explains that the agent only can crossover their genes with an agent of other gender. There are two types of gender: the male agents search actively a couple to crossover information; the female agents receive the corresponding bids and decides if it accepts or rejects the male agent. In the second part, $\alpha$ is factor of selection according to the fitness value, while the $\alpha$ value is closer to 0 , the greater it is the probability of selecting other agent with a higher $\alpha$ value.

The behavior of the agent vehicles, are directly related to actions of selection, crossover and refinement of the evolutionary framework which can be explained in the following pseudo-code:

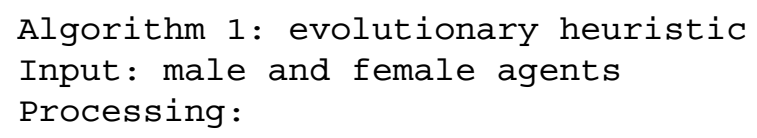



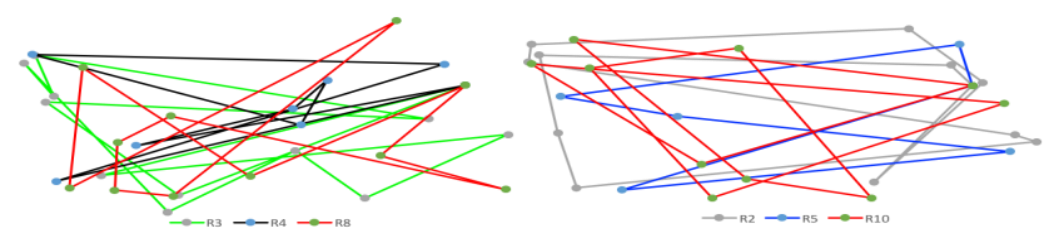

Fig. 3. Some routes of the best run. Left (Solomon) - Right (Evolutionary multi-agent).

(1) Initialize.

(2) Selection between agents according to $B_{i}$.

(3) Crossover the genes of the agents generating $N$ pairs that constitute the population of descending routes.

(4) Assess capacity constraints of each route.

(5) Local search with 2-opt heuristic.

(6) Assess time window constraints.

(7) The Children replace the Parents if their fitness is greater than the parents.

(8) Randomly assigns the gender to the new individuals.

(9) Until stop condition is fullfilled.

\section{$4 \quad$ Model Application}

For the application of the multi-agent model we consider the following sets: the demands of products are in a rank between $(6-29)$ units, the location of customers is between (-100 and 100 units in a Cartesian plane, these values were chosen randomly) and the depot is located at point $(69,-29)$; the capacity of the vehicles is 200 unit. Ten runs were performed with the same data set applying the Solomon insertion heuristic and the evolutionary multi-agent model and each run gives as a result the set of routes that should be taken to meet the demand and the time window constraints with consistent solutions. The analysis of the results for the same data demonstrates that the evolutionary multi-agent model generates an improvement of the results compared with the Solomon heuristic. The best routes produced by the Solomon insertion heuristic and by the proposed evolutionary MAS heuristic are presented in Table 1. As shown in this table, 13 routes are required to visit all the customers, and the evolutionary multi-agent model changes the sequences (must be aware that the routes start and finalize at the depot) of the routes according with the coordination and collaboration process between the agents vehicle producing an improving in the total travel distance.

The best solution for the Solomon heuristic generates a travel distance of 5632,3 units, meanwhile the best solution with the Evolutionary Multi-Agent heuristic is 5327,8 units.

This improvement in the solution, is the result of the coordination and collaboration processes of the agents' vehicle through the evolutionary algorithm. Additionally, Fig. 3 (left side) shows some of the 13 Solomon routes, allowing to observe that the routes are very heterogeneous regarding the position of customers. Due to the time window 
Multi-agent Model for Urban Goods Distribution

Table 1. Best run by Solomon heuristic and Evolutionary multi-agent heuristic.

\begin{tabular}{|c|c|c|c|c|c|c|}
\hline \multirow[b]{2}{*}{ Routes } & \multicolumn{3}{|c|}{ Solomon } & \multicolumn{3}{|c|}{ Evolutionary multi-agent Model } \\
\hline & \multicolumn{2}{|c|}{ Sequence of customers } & Distance & \multicolumn{2}{|c|}{ Sequence of customers } & Distance \\
\hline 1 & \multicolumn{2}{|c|}{$85-91-65-70-81-59-76$} & 392,273 & \multicolumn{2}{|c|}{$26-60-93-66-62-20-3-9$} & 284,871 \\
\hline 2 & \multicolumn{2}{|c|}{$\begin{array}{l}\text { 82-79-99-92-90-88-83- } \\
100\end{array}$} & 284,747 & \multicolumn{2}{|c|}{$34-31-44-21-80-79-70-12$} & 390,258 \\
\hline 3 & \multicolumn{2}{|c|}{$\begin{array}{l}67-56-63-61-64-62-78- \\
75-74-53\end{array}$} & 396,85 & \multicolumn{2}{|c|}{$\begin{array}{c}84-65-4-82-64-15-19-48- \\
73-47-76\end{array}$} & 316,532 \\
\hline 4 & \multicolumn{2}{|c|}{$\begin{array}{l}77-58-48-22-49-45-38- \\
41-33 \\
\end{array}$} & 531,956 & \multicolumn{2}{|c|}{$\begin{array}{c}22-89-88-38-51-55-6-87- \\
56 \\
\end{array}$} & 531,955 \\
\hline 5 & \multicolumn{2}{|c|}{ 89-96-93-94-87-97-84 } & 307,937 & \multicolumn{2}{|c|}{$90-83-74-13-94$} & 326,162 \\
\hline 6 & \multicolumn{2}{|c|}{$\begin{array}{c}\text { 73-54-52-50-66-72-57- } \\
60-44\end{array}$} & 485,804 & \multicolumn{2}{|c|}{$11-28-49-71-32-10$} & 260,548 \\
\hline 7 & \multicolumn{2}{|c|}{$95-98-80-86$} & 335,186 & \multicolumn{2}{|c|}{$7-39-25-98-8-58-92$} & 380,445 \\
\hline 8 & \multicolumn{2}{|c|}{$\begin{array}{l}\text { 43-32-35-19-39-46-27- } \\
\quad 25-21-18\end{array}$} & 531,799 & \multicolumn{2}{|c|}{$\begin{array}{c}27-96-86-68-35-52-2-5- \\
41\end{array}$} & 526,484 \\
\hline 9 & \multicolumn{2}{|c|}{$71-51-34-26-29-16-47$} & 547,915 & \multicolumn{2}{|c|}{$\begin{array}{l}53-37-99-69-78-33-23- \\
57-46\end{array}$} & 547,807 \\
\hline 10 & \multicolumn{2}{|c|}{$40-28-31-42-37-24-11$} & 475,728 & \multicolumn{2}{|c|}{$\begin{array}{l}97-29-40-43-85-61-42- \\
18-14\end{array}$} & 477,982 \\
\hline 11 & \multicolumn{2}{|c|}{$12-4-1-3-36$} & 395,332 & \multicolumn{2}{|c|}{$\begin{array}{c}67-30-45-17-24-100-36- \\
81\end{array}$} & 479,361 \\
\hline 12 & \multicolumn{2}{|c|}{$30-7-6-8-5-15-20-2$} & 486,721 & \multicolumn{2}{|c|}{$75-63-1-95-72$} & 419,465 \\
\hline \multirow[t]{2}{*}{13} & \multicolumn{2}{|c|}{$23-14-17-10-13-9$} & 460,136 & \multicolumn{2}{|c|}{$91-59-16-77-54-50$} & 385,989 \\
\hline & \multicolumn{2}{|c|}{ Total travel distance } & $5.632,38$ & \multicolumn{2}{|c|}{ Total travel distance } & $5.327,86$ \\
\hline & & Table 2. & Comparison $\mathrm{b}$ & tween results & & \\
\hline & Best t & ravel distance & Mean of & ravel distance & Stan & ar deviation \\
\hline Instance & Solomon & $\begin{array}{l}\text { Evolutionary } \\
\text { MAS }\end{array}$ & Solomon & $\begin{array}{l}\text { Evolutionar } \\
\text { y MAS }\end{array}$ & Solomon & $\begin{array}{l}\text { Evolutionary } \\
\text { MAS }\end{array}$ \\
\hline $\begin{array}{c}50 \\
\text { customers }\end{array}$ & $\begin{array}{c}2365, \\
3363\end{array}$ & 2091,0110 & $\begin{array}{l}2455,0 \\
046\end{array}$ & $\begin{array}{c}2234,949 \\
2\end{array}$ & $\begin{array}{l}179,5 \\
701\end{array}$ & 148,2594 \\
\hline $\begin{array}{c}100 \\
\text { customers }\end{array}$ & $\begin{array}{l}5632 \\
3847\end{array}$ & 5327,8640 & $\begin{array}{l}5909,3 \\
218\end{array}$ & $\begin{array}{l}5371,135 \\
9\end{array}$ & $\begin{array}{l}198,1 \\
098\end{array}$ & 168,1545 \\
\hline $\begin{array}{c}200 \\
\text { customers }\end{array}$ & $\begin{array}{l}5919 \\
0469\end{array}$ & 5816,0134 & $\begin{array}{l}6427,3 \\
153\end{array}$ & $\begin{array}{c}6257,466 \\
8\end{array}$ & $\begin{array}{l}221,2 \\
622\end{array}$ & 169,1766 \\
\hline $\begin{array}{c}600 \\
\text { customers }\end{array}$ & $\begin{array}{r}3930 \\
2,2651\end{array}$ & $\begin{array}{l}38896,924 \\
7\end{array}$ & $\begin{array}{l}40941, \\
9605\end{array}$ & $\begin{array}{l}40155,52 \\
18\end{array}$ & $\begin{array}{l}822,8 \\
201\end{array}$ & 732,8047 \\
\hline
\end{tabular}

constraints, the routes are some chaotic and with superposition of trips. In the evolutionary multi-agent heuristic, the routes (right side of Fig. 3) are less complex. 
To validate de results of the Evolutionary MAS, a set of instances were performed with the same heuristics. The set of instances can be found at Serna-Uran (2016) [14] for the set of 50 customers and 200 customers, and for the 600 customer the Solomon benchmark heuristic S-R1-600 was used.

Table 2, presents results of the performance of both algorithms applied in different instances and reinforces that the proposed MAS generates a lower travel distance and a lower variability in the results obtained in each run.

It is remarkable that the Solomon heuristic is a well-known benchmark to solve the CVRPTW, their solutions are feasible but with low efficiency. The presented evolutionary multi-agent heuristic is a novel model to solve this kind of problems and allows the interaction of the goods distribution stakeholders through the coordination and collaboration between them with the aim to find a global solution that is more realistic and efficient in terms of the use of resources and applicability to real problems. The Solomon heuristic as starting point of the evolutionary multi-agent systems allows, at least, to equal the initial routes, and the interaction between agents improve this routes by the behaviors that each agent perform. It should be noted that although the solutions are very near between them, the evolutionary MAS has less variability which means that the solutions are more consistent than Solomon, whereby it could be used in a more dynamic context such as the real world.

\section{Conclusions}

In this paper the capacitated vehicle routing problem with time windows (CVRPTW) was solved using the Solomon Heuristic and a Proposed Multi-Agent Model. The solutions found with the Solomon algorithm are feasible solutions to the Vehicle Routing Problem with time windows, however the space of solutions is not intensively explored from the insertion criteria that the heuristic uses.

This generates that the routes found are little ordered and coherent as can be observed in figure 4 (left side), which can be interpreted as inefficient routes. On the other hand, the solutions found with the evolutionary heuristics are more ordered, more efficient and equally feasible routes in terms of time window compliance that can help in the operational decisions in the UGD.

In the process followed in the implementation of the model, it is possible to highlight the ease with which problems of great computational complexity can be solved from the distributed computing paradigm. In urban conditions, where the complexity is not only computational but also stochastic or for the difficulty to articulate different actors, multi-agent models become an important solution alternative, since those present a great flexibility for the definition of different agents with capacities and conditions, allowing to explore and optimize coordination processes based on behaviors that can be adapted according to the real conditions or scenarios. In the logistic model presented, for example, vehicles are defined as agents, which facilitates the design of collaboration and optimization processes based on particular conditions that can be easily adjusted to urban environments.

The use of fuzzy logic in the relaxation of the constraints of time windows could reduce the cost of the routes with a penalization for violating the time windows, the use of this technique would be interesting for further research. In the same way, inclusion 
of the dynamic context of the UGD in the model according with the permanent changes presented at the demand and in the travel times in the cities is a future research filed.

\section{References}

1. Taniguchi, E., Thompson, R. G., Yamada, T., Van Duin, J. H.: City logistics: Network modelling and intelligent transport systems. Elsevier Science (2001)

2. Zapata-Cortes, J. A.: Optimización de la distribución de mercancías utilizando un modelo genético multiobjetivo de inventario colaborativo de $\mathrm{m}$ proveedores con $\mathrm{n}$ clientes. Tesis Doctoral, Universidad Nacional de Colombia (2017)

3. Arango-Serna, M. D., Zapata-Cortes, J. A., Serna-Uran, C. A.: Collaborative Multiobjective Model for Urban Goods Distribution Optimization. In: García-Alcaraz, J., Alor-Hernández, G., Maldonado-Macías, A., Sánchez-Ramírez, C. (eds) New Perspectives on Applied Industrial Tools and Techniques. Management and Industrial Engineering. Springer, Cham (2018)

4. Bozzo, R., Conca, A., Marangon, F.: Decision support system for city logistics: Literature review, and guidelines for an ex-ante model. Transportation Research Procedia (2014)

5. Wolpert, S., Reuter, C.: Status Quo of City Logistics in Scientific Literature: Systematic Review. Transportation Research Record, 2269(2269), pp. 110-116 (2012)

6. Arango-Serna, M. D., Serna-Uran, C. A., Alvarez-Uribe, K. C.: Collaborative autonomous systems in models of urban logistics. DYNA, 79(172), pp. 171-179 (2012)

7. Anand, N., van Duin, J. H. R., Tavasszy, L.: Framework for Modelling Multi-stakeholder City Logistics Domain Using the Agent based Modelling Approach. Transportation Research Procedia, 16(March), pp. 4-15 (2016)

8. Rushton, P., Croucher, P., Baker, P.: The handbook of logistics and distribution management, 3rd edition. Ed. Kogan Page Limited (2010)

9. Estrada, M. Á.: Análisis de Estrategias Eficientes en la Logística de Distribución de Paquetería. Universidad Politécnica de Cataluña (2007)

10. Arango, M. D., Zapata, J. A., Andres, C.: Metaheuristics for goods distribution. Proceedings of 2015 International Conference on Industrial Engineering and Systems Management (IESM), IEEE Publications. pp. 99-107 (2015)

11. van Lon, R. R. S., Ferrante, E., Turgut, E., Wenseleers, T., Berghe, G., Holvoet, T.: Measures of dynamism and urgency in logistics. European Journal of Operational Research, 253(3), pp. 614-624 (2016)

12. Kammoun, H. M., Kallel, I., Casillas, J., Abraham, A., Alimi, A. M.: Adapt-Traf: An adaptive multiagent road traffic management system based on hybrid ant-hierarchical fuzzy model. Transportation Research Part C, 42, pp. 147-167 (2014)

13. Wooldridge, M.: An Introduction to MultiAgent Systems. (J. Wiley, Ed.) (2001)

14. Serna-Uran, C. A.: Modelo multi-agente para problemas de recogida y entrega de mercancías con ventanas de tiempo usando un algoritmo memético con relajaciones difusas. Doctoral Thesis. Universidad Nacional de Colombia (2016)

15. Corchado, J. M.: Modelos y Arquitecturas de Agente. In Mas.A (eds). Agentes software y sistemas multi-agente: conceptos, arquitectura s y aplicaciones. Prentice Hall (2005)

16. Taniguchi, E., Thompson, R. G., Yamada, T.: Emerging Techniques for Enhancing the Practical Application of City Logistics Models. Procedia - Social and Behavioral Sciences, 39, pp. 3-18 (2012)

17. Bernardi, D., Confessore, G., Stecca, G. A.: Multi-Agent Model Integrating Inventory and Routing Processes. Virtual Enterprises and Collaborative Networks, 149, pp. 107-114 (2004)

18. Sitek, P., Wikarek, J., Grzybowska, K.: A Multi-Agent Approach to the Multi-Echelon Capacitated Vehicle Routing Problem. In Highlights of Practical Applications of 
Martín Darío Arango Serna, Cristian Giovanny Gómez Marín, Conrado Augusto Serna Urán, et al.

Heterogeneous Multi-Agent Systems. The PAAMS Collection pp. 121-132 (2014)

19. Kohout, R., Erol, K.: In-time agent-based vehicle routing with a stochastic improvement heuristic. Proceedings of the 6th National Conference on Arti cial Intelligence (AAAI-99), pp. 864-869 (1999)

20. Zargayouna, M., Balbo, F., Scémama, G.: A multi-agent approach for the dynamic VRPTW. International Workshop on Engineering Societies in the Agents World, pp. 1-15 (2008)

21. Vokrinek, J., Komenda, A., Pechoucek, M.: Agents Towards Vehicle Routing Problems. In Proceedings of the 9th International Conference on Autonomous Agents and Multiagent Systems, pp. 773-780 (2010)

22. Arango-Serna, M. D., Serna-Uran, C. A., Zapata-Cortes, J. A.: Multi-agent System Modeling for the Coordination of Processes of Distribution of Goods Using a Memetic Algorithm. In: García-Alcaraz J., Alor-Hernández G., Maldonado-Macías A., SánchezRamírez C. (eds), New Perspectives on Applied Industrial Tools and Techniques. Management and Industrial Engineering. Springer, Cham (2018)

23. De Oliveira, L. K., Lessa, D. A., Oliveira, E., Ferreira, B., Calazans, G.: Multi-agent modelling approach for evaluating the city logistics dynamic in a vulnerability situation: An exploratory study in Belo Horizonte (Brazil). Transportation Research Procedia, 25, pp. 1046-1060 (2017)

24. Schröder, S., Dabidian, P., Liedtke, G.: A conceptual proposal for an expert system to analyze smart policy options for urban CEP transports. In 2015 Smart Cities Symposium Prague, SCSP¹5 (2015)

25. Cavalcante, R. A., Roorda, M. J.: Freight market interactions simulation (FREMIS): An agent- based modeling framework. Procedia Computer Science, 19, pp. 867-873 (2013)

26. Joubert, J. W.: Analyzing Commercial Through-Traffic. Procedia - Social and Behavioral Sciences, 39, pp. 184-194 (2012)

27. Baindur, D., Viegas, J. M.: An agent based model concept for assessing modal share in inter-regional freight transport markets. Journal of Transport Geography, 19(6), pp. 10931105 (2011)

28. Zulvia, F. E., Kuo, R. J., Hu, T. L.: Solving CVRP with time window, fuzzy travel time and demand via a hybrid ant colony optimization and genetic algortihm. 2012 IEEE Congress on Evolutionary Computation, CEC 2012, pp. 10-15 (2012)

29. Ghiani, G., Laporte, G., Musmano, R.: Introduction to Logistics Systems Planning and Control. West Sussex: Wiley (2004)

30. Foundation For Intelligent Physical Agents. Retrieved from (2015)

31. Wang, H., Zeng, J., Xu, Y., Meng, A., Ye, L., Roy, D., Vacher, J..: Genetic algorithms using multi-objectives in a multi-agent system. Robotics and Autonomous Systems. 33, pp. 179-190 (2005) 